Referencia para citar este artículo: Kriger, M. \& Said, Sh. (2017). Hacer política desde la escuela: narrativas biográficas de jóvenes en Argentina. Revista Latinoamericana de Ciencias Sociales, Niñez y Juventud, 15 (2), pp. 1085-1096. DOI:10.11600/1692715x.1521920122016

\title{
Hacer política desde la escuela: narrativas biográficas de jóvenes en Argentina*
}

\author{
MIRIAM KRIGER ** \\ Docente-Investigadora de la Universidad de Buenos Aires, Argentina. \\ SHIRLY $\boldsymbol{S}_{A I D}{ }^{* * * *}$ \\ Becaria doctoral Consejo Nacional de Investigaciones Científicas y Técnicas-Conicet, Argentina.
}

\section{Artículo recibido en diciembre 20 de 2016; artículo aceptado en marzo 17 de 2017 (Eds.)}

- Resumen (analítico): este artículo trata sobre el papel de la escuela en el encuentro de los y las jóvenes con la política en la Argentina de los años siguientes al Bicentenario (2010). Presentamos narrativas de militantes de distintos espacios políticos, con el objetivo de indagar el rol que asignan a la escuela en sus trayectorias, desde las perspectivas de la socialización y la subjetivación política, con sustento en aportes de la sociología de la individuación. Tomamos para ello sus argumentaciones expuestas en dos debates grupales realizados en 2012 y 2013, en torno a temas clave de la agenda juvenil: la memoria estudiantil de la última dictadura cívico-militar, condensada en el relato de "La noche de los lápices", y la ampliación del voto a los 16 años de edad, promulgada por ley en 2012.

Palabras clave: política, escuela, militancia estudiantil, politización juvenil, socialización política, subjetivación política, individuación (Tesauro de Ciencias Sociales de la Unesco).

\section{Engaging in politics at school: biographical narratives of militant student youth in the bicentennial Argentina}

- Abstract (analytical): This article is about the role of school in young people's interactions with politics in Argentina following the country's bicentennial year (2010). The authors present narratives of young activists from different political spaces with the aim of investigating the role that school has had in their trajectories, with a particular focus on their socialization and political subjectivation, incorporating contributions from the Sociology of Individuation. For this purpose, the authors take the arguments that were presented in two group discussions in 2012 and 2013 regarding two key issues for the youth agenda: student memory of the most recent civic-military dictatorship, condensed in the story titled "The Night of the Pencils", and the change in legislation so that young people aged 16 and older can vote in elections, which was passed in 2012.

Key words: politics, school, youth militancy, students politicization, political socialization, political subjectivation, individuation (Unesco Social Science Thesaurus).

\footnotetext{
Este artículo de investigación científica y tecnológica fue realizado en el marco del Proyecto PICT 2012-2751 (Dirección: Dra. Miriam Kriger). Agradecemos también el aval de los proyectos Ubacyt 20020110200204 y Ubacyt 20020120200320 . Nombre de la investigación: "Juventud, política y nación: Un estudio sobre sentidos, disposiciones y experiencias en torno a la política y el proyecto común". Fechas investigación: enero de 2014-diciembre de 2016. Area de conocimiento: Sociología; subárea: Sociología.

** Dra. en Ciencias Sociales, Investigadora Adjunta del Consejo Nacional de Investigaciones Científicas y Técnicas (Conicet) con sede en el CISConicet/Ides, Docente Investigadora de la Universidad de Buenos Aires (UBA). Orcid: 0000-0002-8718-4089. Índice H5: 10. Correo electrónico: mkriger@gmail.com

*** Lic. en Sociología y Doctoranda en Ciencias de la Educación en la Universidad de Buenos Aires (UBA), becaria doctoral del Consejo Nacional de Investigaciones Científicas y Técnicas (Conicet) con sede en el CIS-Conicet/Ides. Orcid: 0000-0002-7937-8772. Índice H5: 1. Correo electrónico: shirlysaid@gmail.com
} 


\section{Fazer política desde a escola: narrativas biográficas de jovens militantes estudantis na Argentina do Bicentenário}

- Resumo (analítico): Este artigo é sobre o papel da escola no encontro dos jovens com a política na Argentina após o ano do bicentenário (2010). Apresentam-se narrativas de jovens ativistas de diferentes espaços politicos, com o objetivo de investigar o papel atribuído a escola nas suas trajetórias desde as perspectivas da socialização e subjetivação política, com contribuições da sociologia da individuaãção. Tomamos portanto os argumentos que apresentaram-se em duas discussões grupais em 2012 e 2013, sobre duas questões chave da agenda da juventude: a memória estudantil da última ditadura cívico-militar, condensada na história de "A noite dos lápis", e a extensão do voto a 16 anos de idade, criado por lei em 2012.

Palavras-chave: política, escola, militância estudante, politização da juventude, socialização política, subjetivação política, individualização (Thesaurus de Ciências Sociais da Unesco).

-1. Presentación y contextualización. -2. Marco teórico y antecedentes. -3. Las narrativas de los y las jóvenes. -4.a. Primer debate: "La noche de los Lápices". -4.b. Segundo debate: el "voto joven". -5. Discusión y conclusiones: la política como "sub-prueba" escolar. -Lista de referencias.

\section{Presentación y contextualización}

En este artículo analizamos el lugar de la escuela como ámbito de encuentro con la política en la Argentina reciente (2012-2013), en un momento de particular politización juvenil. La primera década del nuevo siglo se caracterizó a nivel global por la positivización de los sentidos de la política, tras su crisis de legitimidad (Touraine, 1997) a finales del anterior, así como por un aumento de la participación y visibilidad de las personas jóvenes, que tuvo expresiones particulares en América Latina (Vommaro, 2015).

En el contexto de nuestro estudio, la crisis de 2001 (Giarracca, 2001) y el "argentinazo" marcaron un punto de viraje en el relato colectivo, con el colapso integral del "proyecto común" y la necesidad inmediata de su reconstrucción (Kriger, 2010). Desde el 2003, en un clima de "rearticulación de la institucionalidad estatal" (Aguiló \& Wahren, 2014), se habilitaron las condiciones para una recuperación de la política que concedió un rol central a la juventud como sujeto histórico, promocionando su participación y la integración de sus activismos formales, como los partidos políticos (Kriger, 2016; Núñez, 2012). Hacia

1 Este término remite a la crisis política, económica, social e institucional que estalló en Argentina en diciembre de 2001, mediante una revuelta popular generalizada que causó la renuncia del entonces presidente Fernando de la Rúa. el final de la primera década del milenio era posible constatar un aumento de la politización juvenil construida por los propios actores no solo desde abajo ${ }^{2}$-en movimientos, partidos y organizaciones estudiantiles-, sino también desde arriba -como un proceso de "consagración de la juventud como causa militante" (Vázquez, 2013) y de la condición juvenil (Vommaro, 2015)- por parte del Estado y de la clase política en todo su espectro: desde el kirchnerismo -con una narrativa propia sobre la militancia juvenil (Vázquez, 2015)- hasta los partidos de centro-derecha, como el PRO -con un discurso centrado en la moral y el voluntariado (Dukuen \& Kriger, 2016; Vommaro, Morresi \& Bellotti, 2015)-. Estas dos tendencias -la politización desde abajo y desde arriba- convergieron en lo que hemos caracterizado como "última invención histórica de la juventud" (Kriger, 2016), promovida por el Estado mediante políticas públicas e interpelaciones discursivas, cuyo rasgo clave fue la institucionalización del vínculo entre juventud y política, destacándose la promulgación de las leyes de "Voto joven" y de Centros de Estudiantes ${ }^{4}$.

2 Con las expresiones "desde arriba" y "desde abajo" nos referimos alegóricamente a los agentes protagonistas, aludiendo la primera a la producción estatal y política, y la segunda a la construcción de los actores desde la base social, recuperando el uso que le da Svampa (2001) para referirse a movimientos populares.

3 Ley $\mathrm{N}^{\circ} 26.774 / 2012$.

4 Ley No 26.877/2013. 
En este marco, hablamos de politización para referirnos a "un proceso que tiende a una mayor articulación genuina entre el Estado y la sociedad civil, entre la política y lo político (Lefort, 1992), entre lo de arriba y lo de abajo" (Kriger, 2016, p. 24), más aún tras su virtual divorcio en el 2001. No aludimos a puntos de llegada, sino a matices de procesos complejos ligados a las transformaciones de la sociedad y a la conversión cultural de los sujetos sociales en políticos, que es a lo que llamamos subjetivación política. Esta puede pensarse como dimensión psicosocial de la politización, atravesada a su vez por "procesos dinámicos de los que participan múltiples dimensiones psicológicas, que al entramarse socialmente hacen sentido y experiencia (Kriger, 2016, p. 23).

Teniendo en cuenta hallazgos de investigaciones de 2005-2007 y 2011-20135, donde los jóvenes ${ }^{6}$ entrevistados consideraban la escuela como el primer lugar donde se hablaba de historia, política y derechos humanos, nos preguntamos: ¿cómo se produce el encuentro de los estudiantes con la política, en este contexto particular? ¿Cuál es el lugar que le asignan a la escuela, en su proceso de politización, jóvenes que han elegido la militancia? Proponemos como hipótesis que ésta es no solo un ámbito clave de formación de pensamiento político sino también de encuentro vivencial de esta generación con la política.

En virtud de ello, presentamos en este trabajo narrativas de jóvenes -autodefinidos como "militantes"- acerca de su experiencia con la política y el rol de la escuela en su trayectoria. Tomamos como objeto sus relatos biográficos, expuestos en dos debates grupales: uno sobre la "La noche de los lápices", realizado en 2012, y

5 Nos referimos a la investigación doctoral (Kriger, 2007) y al proyecto de investigación "Comprensión histórica, conocimiento social y formación política. Un estudio empírico de las representaciones de jóvenes ciudadanos argentinos escolarizados" dirigido por la Dra. Miriam Kriger (Ubacyt 20020090200377 2010-2012).

6 En algunas partes de este artículo hemos decidido utilizar genéricamente "los" jóvenes, en lugar de referirnos en cada ocasión a "los jóvenes y las jóvenes", para agilizar la lectura. Sin embargo, no desconocemos ni avalamos la desigualdad entre géneros ni su expresión en el lenguaje, e invitamos a tener presente la cuestión de género a lo largo de la lectura como una dimensión analítica fundamental. otro sobre el "voto joven", en 2013; temas que vertebraron la agenda pública juvenil y cuyo tratamiento adquiere significación.

El primero refiere a un relato emblemático de la represión dictatorial, conocido como " $\mathrm{La}$ noche de los lápices"7, que condensa el ejercicio de una memoria estudiantil de amplísimo consenso, pero donde la condición activa de los protagonistas fue invisibilizada junto con su pertenencia política (Lorenz, 2006; Raggio, 2006). Este leitmotiv fue arena de luchas del movimiento estudiantil en los últimos años, en los que la politización juvenil se intensificó y entraron en pugna diferentes posiciones políticas. A partir del 2011, la marcha del 16 de septiembre se desdobló entre diferentes asociaciones políticas, disolviéndose el efecto totalizador que desde los años 90 se había sostenido sobre las prácticas colectivas, aunque no su presencia en el espacio propiamente escolar (Kriger, 2016).

El segundo tema, la ley que amplía el voto opcional a los 16 años, es un hecho representativo de la invención de la juventud, ya que no surgió en respuesta a una demanda específicamente juvenil ni a modalidades políticas propias, sino como iniciativa adulta $\mathrm{y}$ oficial que -desde arriba- vino a impulsar su incorporación como ciudadanos políticos, aunque luego haya sido apropiada y resignificada por los jóvenes. Esta ley abrió un gran desafío: la entrada de la política partidaria -con su conflictividad particular- a una escuela que tradicionalmente ha considerado la política "disolvente y ajena a la noción de patria" (Romero et al., 2004, p. $57)^{8}$.

Tomando las voces de militantes acerca de cómo ha sido su experiencia y cuáles son sus ideas en torno a estos dos tópicos, en este trabajo intentaremos comprender el rol de la escuela en este período, en la socialización y subjetivación política juvenil, desarrollando

7 "La Noche de los Lápices" alude, con el nombre que la bautizaron los mismos represores, a la historia del secuestro -el 16 de septiembre de 1976- y posterior tortura de nueve estudiantes secundarios. Seis de ellos continúan desaparecidos.

8 La Ley de Centros de Estudiantes de 1984 desalentaba el accionar de los partidos políticos en las escuelas, concebidos como espacios de discordia "reñidos con el civismo" (Manzano, 2011, p. 48). Su nueva versión (ver nota $\mathrm{N}^{\circ} 5$ ) no menciona la palabra "política" ni una sola vez. 
aportes teórico-metodológicos de la sociología de la individuación.

\section{Marco teórico y antecedentes}

Proponemos vincular los procesos de politización, que tienen como ámbito inicial la escuela, con aquellos más amplios de individuación que atraviesan los jóvenes y las jóvenes, a partir de la confluencia de las tres vías de análisis que propone Martuccelli (2007): socialización, subjetivación e individuación.

Tomamos de Berger y Luckmann (1989 [1968]) el concepto de socialización secundaria, entendida como la "internalización de submundos institucionales o basados sobre instituciones" (1989, p. 174), para hacer referencia a los procesos formativos en la escuela; y de Dubet y Martuccelli (1998) la caracterización de la función socializadora de la escuela, encargada de producir "un tipo de individuo adaptado a la sociedad en la cual vive, retomando la herencia que toda educación transmite" (1998, p. 27).

En cuanto a la socialización política juvenil, su estudio fue abordado en los últimos años desde múltiples perspectivas $\mathrm{y}$ en referencia tanto a instituciones tradicionales -sindicatos, partidos políticos, escuela- como a movimientos sociales, organizaciones territoriales y colectivos juveniles (para un estado del arte: Bonvillani, Palermo, Vázquez \& Vommaro, 2008).

En relación con nuestro tema, recuperamos los trabajos que toman la escuela como ámbito de construcción de subjetividades y producción de socialización política (Dukuen \& Kriger, 2016; Núñez, 2008; Palacios-Mena \& HerreraGonzález, 2013).

En el plano de la subjetivación política, partimos de la concepción de que los individuos son siempre sujetos sociales -que atraviesan procesos de socialización- pero no necesariamente llegan a ser sujetos políticos plenos (Kriger, 2010). En términos de Martuccelli (Martinic \& Soto, 2010), "el sujeto nunca precede, no es algo que está dado (...). Supone una lógica de emancipación explícita o implícita, es decir, no todos somos sujetos, solo algunos logran serlo" (2010, p. 7). En esta línea, Bonvillani (2012) distingue entre perspectivas que conciben la subjetividad política como una mera zona de intersección entre terrenos de la subjetividad y la política, y aquellas que la ven como resultado de un proceso de subjetivación dinámico, donde el individuo despliega agencia y reflexividad. Es decir, un proceso que, enmarcado en un reto colectivo, requiere un trabajo específico de los individuos (Said \& Kriger, 2016).

Aquí es donde la "sociología de la individuación" (Martuccelli, 2007) realiza un aporte ante el diagnóstico según el cual la época actual se caracteriza por un clima de riesgo e incertidumbre, signado por el debilitamiento de las instituciones y por factores estructurales que en la modernidad contenían a los sujetos. Al respecto, Martuccelli (Martinic \& Soto, 2010) propone invertir el orden del análisis social: tomar como nuevo operador analítico de la sociología las experiencias individuales, para conocer el proceso de "fabricación" de los individuos desde abajo, rechazando las concepciones sistémicas.

Aquí la noción de "prueba" (Martuccelli, 2007) resulta central: se refiere a los desafíos que "circunscriben un conjunto de grandes retos estructurales, particularmente significativos" (2007, p. 125) para cada sociedad. El trabajo realizado para afrontar las pruebas constituye el principal vector del proceso de individuación, siendo su experiencia de éxito o fracaso para superarlas lo que marca las trayectorias de los individuos. Si bien existen muchos tipos de pruebas, en esta investigación centramos nuestra atención en la prueba escolar, considerada una de las más significativas, aún en sociedades diferentes (Martuccelli \& De Singly, 2012; Araujo \& Martuccelli, 2010).

Nos preguntamos, entonces, por las relaciones entrelaexperienciapolíticaestudiantil y la "prueba escolar" en el contexto estudiado: ¿Puede ser la participación política un desafío de este tipo, que los sujetos militantes jóvenes asumen como constitutivo de la experiencia escolar? Y, en ese caso, ¿cómo se posicionan ante tal prueba, tanto individualmente como frente a otros estudiantes? 


\section{Las narrativas de los y las jóvenes}

Basamos el estudio en narrativas provenientes de dos debates grupales, en los que participaron jóvenes entre 16 y 19 años de edad $^{9}$, militantes de distintos espacios partidarios y/o agrupaciones políticas. Ambas discusiones tuvieron lugar en un ámbito virtual ${ }^{10}$ coordinado por una de las autoras a partir de un guión semiestructurado. El primero, realizado en 2012, tuvo como eje "La noche de los lápices", y participaron tres jóvenes egresados del colegio secundario el año anterior: Dolores, militante de La Cámpora -organización juvenil de origen estudiantil, aunque con despliegue multisectorial, afín al kirchnerismo-; Luna, de la Unión de Juventudes por el Socialismo del Partido Obrero (UJS-PO) -partido político de izquierda trotskista-, y Gonzalo, de la Franja Morada -rama estudiantil de la Unión Cívica Radical, tradicional partido político de centroderecha-. En el segundo debate, realizado en 2013, se abordó los posicionamientos de los jóvenes y las jóvenes frente a la "ley de voto joven", y participaron Julián, egresado del colegio el año anterior y militante de Lobo Suelto -rama estudiantil de la organización de "izquierda independiente" Marea Popular (MP)-; Pedro, estudiante de $4^{\circ}$ año y militante del Movimiento Evita (ME) -organización de base territorial, peronista, afín al kirchnerismo-, e Ignacio, estudiante de $5^{\circ}$ año y militante de la Unión de Juventudes por el Socialismo del Partido Obrero (UJS-PO).

Es preciso aclarar que no asumimos la escuela en su dimensión pedagógica ni institucional, sino como ámbito de socialización desde las narrativas de los jóvenes y las jóvenes. En tal sentido, reconociendo el potencial subjetivante de la propia narración de sí -y del "nosotros"- que se habilita en el espacio biográfico (Arfuch, 2002), asumimos también al lenguaje como lugar posible para el proceso de subjetivación (Said \& Kriger, 2014).

Comenzaremos a presentar los hallazgos de este estudio, analizando algunos aspectos

9 Los nombres de los participantes han sido modificados para mantener su privacidad.

10 Los debates se realizaron en el campus virtual del Área de Educación y Ciencias Sociales (Directora: Miriam Kriger) de Centro Redes http://cursos.centroredes.org.ar/

Rev.latinoam.cienc.soc.niñez juv 15 (2): 1085-1096, 2017 http://revistalatinoamericanaumanizales.cinde.org.co

DOI: $10.11600 / 1692715 \times .1521920122016$ transversales en torno a cómo relatan los jóvenes y las jóvenes su encuentro con la política, y el rol que asignan a la escuela en su socialización y subjetivación política.

Encontramos rasgos comunes respecto al ámbito y a los modos en que ello ocurre:

"Mi historial militante comienza en mi colegio cuando tuve mi primer acercamiento al centro de estudiantes en el año 2008. (...) En el año 2011 ingreso a una agrupación de izquierda independiente en mi escuela y luego, después de varias experiencias como la del Frente Darío Santillán y otras experiencias propias de mi colegio, decidí ingresar a Marea Popular" (Julián).

"Mi primer acercamiento a la militancia fue a fines de 2011 en la agrupación del Centro de Estudiantes de mi colegio de la UJS. A partir de mi militancia en ese espacio y luego de discusiones me incorporé orgánicamente al Partido Obrero a principios de 2013" (Luna).

"Con idas y venidas, pasando por agrupaciones estudiantiles $y$ organizaciones políticas (como La Cámpora), desde hace un año que estoy en el Movimiento Evita" (Pedro).

Notamos que hay un proceso de intensificación del vínculo con la política donde cobra presencia el cuerpo, que discursivamente se expresa mediante el uso de términos que van in crescendo: "involucrarse", "participar", "militar", "ingresar", e "incorporarse orgánicamente". Asimismo, vemos que se proponen recorridos que implicaron dudas y certezas: Julián señala haber pasado por "varias experiencias", Luna por "discusiones" y Pedro por "idas y venidas", antes de sumarse a su espacio actual de militancia, remarcando su autonomía para elegir y eventualmente cambiar de ámbito.

Más allá del aula, la escuela se presenta como el lugar donde construir sus propias apuestas políticas, cuestionar lo establecido y proponer lo nuevo. Allí es donde se abren múltiples opciones de participación para jóvenes: el centro de estudiantes, las agrupaciones propias de cada escuela, las ramas estudiantiles de partidos, etc. 
"Como estudiantes, sentíamos la necesidad de no quedarnos parados frente a las cosas con las que no estábamos de acuerdo. Y qué mejor que participar en el ámbito más cercano que teníamos, por donde pasábamos todos los días, como era el colegio" (Gonzalo).

“¿Qué mejor lugar para los jóvenes para debatir política que la escuela, lugar al que asistimos día a día y donde nos formamos como individuos en un ámbito colectivo de participación?" (Nacho).

Encontramos que también se reconocen, aunque con menos intensidad, otros agentes de socialización política, especialmente la familia, en muchos casos resignificada desde la lectura militante del presente como un antecedente de su ser político.

Ante la pregunta a los jóvenes por el motor de su militancia, Julián cuenta que comenzó a partir de "la pelea por la mayor participación de los estudiantes en las decisiones internas de la escuela", Gonzalo y Luna plantean una "necesidad" de involucrarse en el mundo que los rodea para cambiarlo y hacerlo más justo, Pedro recupera la memoria emotiva de una asamblea de la que participaba con su padre en los años 90, Dolores plantea que "para que se cumplan los derechos, uno debe luchar toda la vida", y Nacho se refiere al asesinato de Mariano Ferreyra ${ }^{11}$ como hecho que lo marcó "muy profundamente" y por el cual se acercó a la política.

Mientras Julián habla de "historial militante" y "realización personal", Pedro alude a una "relación" que enraíza en su infancia, y Dolores se propone luchar "toda la vida". En los relatos de vida la política aparece entretejida con la biografía, vertebrando la identidad y la historia personal de estas personas jóvenes.

\section{4.a. Primer debate: "La noche de los Lápices"}

Analizaremos el debate realizado en el año 2012 en torno al relato estudiantil de la dictadura militar. En las narrativas identificamos

11 Mariano Ferreyra fue un joven militante del Partido Obrero y dirigente estudiantil asesinado en 2010, a los 23 años de edad, mientras apoyaba la protesta de trabajadores tercerizados. dos sentidos superpuestos de "La noche de los lápices": a) una memoria común que toma la escuela como ámbito de participación y reivindica el activismo estudiantil como un valor en sí mismo, independientemente del contexto histórico; y b) una disputa por la lectura política desde el presente, ligada a los posicionamientos ideológicos de los jóvenes y a sus adscripciones político-partidarias.

En principio, los participantes inician su relato vinculando directamente la fecha con la vivencia escolar:

"Mi experiencia con la Noche de los Lápices por supuesto comienza en el colegio. Todos los años se hace un acto, $y$ es especial porque lo hace el centro de estudiantes (al igual que el del 24 de marzo). Se generan situaciones muy significativas, con debates ideológicos en los cuales yo aprendi muchísimo" (Dolores).

"Mi experiencia de La noche de los lápices es muy variada. En mi colegio suele haber jornadas de reflexión para esa fecha, conseguidas y organizadas por el Centro de Estudiantes" (Luna).

Como vemos, ambas señalan el carácter formativo de estas instancias y remarcan el hecho de que son organizadas por estudiantes. A su vez, coinciden en darle carácter político a "La noche de los lápices", y resignificarla desde el presente como un hecho relevante en su militancia estudiantil.

Ahora bien, a medida que profundizan el relato, la dimensión política hace aflorar tensiones $\mathrm{y}$ diferencias asociadas a distintos posicionamientos: en el caso de las organizaciones afines al kirchnerismo se prioriza la "memoria"; y en el de las agrupaciones opositoras, autodenominadas "independientes", la denuncia de las violaciones a los Derechos Humanos en el presente. Dolores cuenta:

"Mi primera experiencia en una marcha de La noche de los lápices fue con los chicos de la FES, y fue alucinante, nunca había estado en una marcha así, porque éramos todos pibes, de secundario, salvo contadas excepciones, y hubo un acto de cierre donde hablaron muchos chicos de diferentes agrupaciones ligadas al 
kirchnerismo; fue muy emocionante escucharlos, esos pibes eran cuadros politicos, ellos reflejaban muy bien cuál era la razón de estar ahí, los militantes secundarios, chicos de 15, 16, 17 años."

Como vemos, Dolores enfatiza que la razón para "estar ahí" eran los "militantes secundarios" asesinados en 1976. A su vez, remarca su admiración hacia los "cuadros políticos" que hablaron; armando un relato donde la política aparece como epifanía (Denzin, 1989), asociada a su identidad como joven y como estudiante.

En la descripción de Luna sobre el modo de abordar la fecha encontramos diferencias notorias, que podemos asociar a la adscripción político-partidaria de cada una:

"[Se realizan] actividades conmemorativas, pero no solo, también buscamos una memoria activa en cuanto a temas que si bien no son explícitamente lo mismo tienen bastante que ver. Ejemplos de esto son los crímenes de Kosteki, Santillán y Mariano Ferreyra, las desapariciones de Julio López y de Luciano Arruga ${ }^{12}$, los casos de gatillo fácil y demás. Se trata de ver más allá de eso-La noche de los lápices-y ver que es algo que sigue existiendo (claro, en menor medida y es mucho más mediatizado), y es algo por lo que tenemos que seguir luchando, no solo 'recordar'."

La tensión entre pasado y presente se hace visible; y también parece expresarse en las fronteras que se trazan entre los jóvenes que no participan en política y quienes sí lo hacen. Como relata Luna:

"Contando desde mi experiencia en un centro de estudiantes bastante politizado, el estar en una agrupación o militar en algún espacio se suele ver como algo "negativo", incluso entre compañeros

12 Se refiere a casos de represión policial, violencia institucional y desapariciones forzadas en democracia. Maximiliano Kosteki y Darío Santillán son dos activistas "piqueteros" asesinados por la policía en una movilización en 2002; Jorge Julio López fue desaparecido el día en que debía dar testimonio contra Miguel Echecolatz, su captor durante la última dictadura militar; y Luciano Arruga fue un joven de 16 años de clase baja torturado en una comisaría y desaparecido en el 2009 tras haber sido detenido por la policía. Sobre Mariano Ferreyra, ver nota $n^{\circ} 13$. activistas. Por ejemplo, muchas veces la palabra del "independiente" (el que no está en ninguna agrupación) tiene más valor y es más escuchada que la del militante."

El riesgo de ser "militante" sería estar influenciado por una línea de pensamiento orgánica, mientras que ser "independiente" aludiría a un compromiso genérico, supuestamente dotado de mayor legitimidad. Dolores coincide:

"A quien no pertenece a una agrupación política se lo escucha más o se le da más valor (...) el que escucha siempre piensa que le querés bajar línea, o piensa que ya sabe lo que vas a decir porque te ven como un estereotipo."

Según plantean, al militante se le tiene "rechazo" o hay prejuicios hacia él, pero eso no parece desanimar su participación. Por el contrario, las lleva a remarcar que no pertenecen a un estereotipo, e incluso a asumir un rol responsable frente a otros jóvenes. En esta tónica, Dolores asegura que su generación "ha visto renacer la política", y que no haber vivido los momentos de desencanto les da "una visión más fresca”. Gonzalo señala:

"Me siento orgulloso de formar parte de una generación que se vuelve a acercar a la política, luego de los nefastos [años] 90. Hoy en día, nosotros cargamos con la responsabilidad de seguir consolidando este sistema democrático, y garantizar su permanencia para el futuro."

Dolores relata lo que sintió la primera vez que participó de una marcha por "La noche de los lápices":

"Por ese entonces yo todavía no militaba, $y$ realmente fue uno de esos momentos quiebre donde me dije, yo quiero hacer eso, quiero militar, quiero ser parte de algo así."

Notamos que, incluso desde lecturas y posicionamientos políticos divergentes respecto a cómo abordar esta fecha histórica, estos jóvenes coinciden en el compromiso de ampliar la participación política de sus pares, y perciben que esto los distingue del resto. 


\section{4.b. Segundo debate: el "voto joven"}

Presentamos ahora fragmentos del debate grupal en torno al "voto joven" (2013). En primer lugar, nos preguntamos cómo valoran los jóvenes la ampliación del voto, y notamos que, aunque no hay una posición unívoca respecto a quién impulsó la ley, la lectura es positiva:

"Desde el PO y el FIT estamos totalmente de acuerdo con el voto joven en sí, entendiendo que es una reivindicación histórica de la juventud" (Nacho).

"Estoy muy contento con ver a los jóvenes de 16 y 17 años yendo a votar (...) Llegamos a un momento socio-histórico en el que la militancia joven era tal que exigía el derecho al voto" (Julián).

Como vemos, Nacho y Julián hacen una reivindicación histórica del "voto joven", como un resultado fáctico de la militancia, aun cuando es sabido que esta iniciativa no partió de la agenda política juvenil. Pedro, en cambio, sí reconoce la Ley como una iniciativa oficial:

"Creo que el voto joven es perfectamente coherente con las politicas que viene llevando a cabo el gobierno nacional con respecto a la ampliación de derechos y el fomento de la participación politica."

Esta divergencia, que podemos vincular a sus filiaciones partidarias y a su relación con el entonces oficialismo -del cual Nacho y Julián se distinguen, y con el que Pedro se identifica-, recorre el debate, pero no impide que haya otros puntos de acuerdo en sus posturas. Aún con matices, coinciden en capitalizar esta ampliación del voto para impulsar la participación juvenil, que reconocen como previa a la ley.

"La participación joven es un hecho existente (sino, no existiría Marea Popular), pero creo fielmente que su condición política no solo no empieza ni termina en la urna, sino que justamente el sufragio es la confluencia de una participación, una concientización y un interés mucho más grande” (Julián).

"La juventud hoy cumple un rol central en la vida política de la Argentina, y a partir del voto joven tiene en sus manos el poder, junto con los demás ciudadanos, de repudiar en las urnas lo que repudia día a día en las calles" (Nacho).
¿Y qué influencia tendrá esta ley sobre la participación política juvenil en general? Nacho y Julián ven en la ampliación del voto un reconocimiento que activa lo que, desde su perspectiva, ya venía sucediendo: un aumento de la participación promovida por los propios jóvenes. Pedro, en cambio, enfatiza la potencia de la Ley a futuro, y la posibilidad de que la juventud sea más escuchada:

"Es una nueva voz que no solo se escucha en las urnas, sino que tiene más fundamentos para ser escuchada con cotidianeidad por toda la sociedad. En general fue bien aceptada la medida, pero la realidad es que queda una gran mayoría de jóvenes sin participar y sin votar."

Pedro se concentra menos en recuperar los logros que en remarcar los desafíos pendientes, e inaugura un interrogante sobre el que giran gran parte de las intervenciones: ¿Cómo interpelar a los jóvenes que no están interesados en participar? En este sentido, todos coinciden en que hay mucho camino por recorrer, analizan las características del desinterés y realizan propuestas que van en dos direcciones: hacia arriba, cuando responsabilizan al Estado y le demandan una profundización de las políticas orientadas a la participación juvenil; y hacia abajo, cuando se muestran ellos mismos comprometidos en el involucramiento de otros jóvenes, que asumen como una responsabilidad. Veamos qué cambios consideran que debería hacer la escuela:

"Con el tiempo la participación va a ir aumentando, cuando se estabilice culturalmente que la juventud es un actor político, y también ocurra un cambio en la educación" (Pedro).

Por su parte, Julián también le asigna a la educación un lugar central, y pone el énfasis en su impronta estatal, refiriéndose al "sistema educativo":

"Creo que en la escuela secundaria, y por ende en el sistema educativo y en cada uno de los aspectos de la educación, se debería tener en cuenta el hecho de que más de la mitad de los estudiantes promedio secundarios votan." 
Ambos recuperan la referencia a la escuela como espacio importante de participación, y asignan relevancia a la existencia de políticas públicas, aunque plantean diferencias en torno al papel que debe jugar la juventud en su diseño e implementación:

"Es imprescindible empoderar a la juventud como sujeto político, y el Estado tiene que usar todas las herramientas que tenga, y la más importante es la educación" (Pedro).

"La escuela debería entender al estudiante justamente como un sujeto político, integrando dicha condición al sistema de enseñanza" (Julián).

Un interrogante clave aparece: ¿Cómo se concibe a la juventud: como destinataria o como generadora de políticas públicas? Mientras que, según Pedro, es necesario "empoderarla" -y el responsable de hacerlo es el Estado-, Julián plantea que el estudiante es un sujeto político en sí, y que la escuela debe "entenderlo" como tal. Esta discusión, acerca de si la capacidad política es inherente o no a la condición juvenil, se expresa también en los posicionamientos en torno a la prohibición de partidos en la escuela, como plantea Nacho:

"Si el fin de la ley es ampliar los derechos y fomentar la participación juvenil, debe existir una apertura total a los partidos en las escuelas secundarias con debates organizados y garantizados - esta última característica no se da-por los Colegios y sus autoridades, debe permitirse la militancia partidaria dentro de las escuelas y a su vez deberían poder elegirse candidatos jóvenes y delegados gremiales a partir de los 16 años, cosa que actualmente no sucede."

Nacho reconoce el rol del Estado como promotor de la participación, pero le exige profundizar las iniciativas a fin de garantizar una entrada completa del juego político a la vida de los jóvenes. Julián adhiere:

"Si la política llegó ya oficialmente a las escuelas, es necesario que los partidos políticos entren. (...) si no nos dejan a los estudiantes poder transmitir el proyecto que defendemos, están dejando que solo haya una versión de la historia: la del gobierno."

En los planteos de estos jóvenes se remarca que la política ya ha ingresado a la vida escolar, y que el Estado debe reconocerlo. Introducen la dimensión del abajo, y se vuelcan a las estrategias que ellos mismos pueden desplegar, sin asignarle al voto el rol organizador de las prácticas juveniles. Nacho lo remarca:

"Personalmente entiendo que el voto joven es, y debe ser usado por los jóvenes, como una herramienta más en las diversas luchas que se dan día a día. En el marco de la educación es una herramienta que se suma a las movilizaciones, cortes de calle, tomas, festivales. Incluso los jóvenes que no militan, supuestos 'ajenos' a la situación, adquieren su experiencia en los ámbitos cotidianos donde desarrollan su vida diariamente y donde realmente se encuentra la política dentro de la juventud: en los colegios, en las universidades, en los trabajos y en los barrios."

En esta línea, Julián plantea:

"Los espacios de militancia extraelectorales han crecido y los debates fueron creciendo cuantitativa $y$ cualitativamente al margen de los debates electorales. Esto nos llevó a los militantes a contagiar nuestras posturas y a integrar a los jóvenes 'desconfiados', y no creo que esto sea labor del voto sino nuestra. Ahora, sin duda, el voto ayuda, jajá..."

Se habla de jóvenes "ajenos" y "desconfiados" de la política, que los activistas tienen la responsabilidad de "contagiar". Pedro dice:

"Es nuestra tarea como militantes concientizar a nuestros compañeros sobre su deber cívico y su oportunidad histórica."

En los tres casos -y de modo similar al debate anterior-detectamos que se sienten responsables de transmitir el compromiso político a los jóvenes que aún no participan. 


\section{Discusión y conclusiones: La política como "sub-prueba" escolar}

Finalmente, señalamos que existe una integración significativa de la política en los relatos biográficos de los jóvenes militantes y que, si bien las motivaciones para la participación son variadas, la escuela aparece siempre como espacio de iniciación. Se presenta como la institución que puede ser cuestionada, pero también instituida y construida, es decir: vivida no sólo como ámbito de transmisión sino de creación.

En este sentido, se reconoce la escuela como lugar histórico y de luchas juveniles emblemáticas -como lo refleja el relato de "La noche de los lápices"-, y también como espacio recuperado para la construcción política en clave generacional, en contraposición a lo supuestamente sucedido en la década previa. Es interesante en este sentido que "el 2001" aparece como punto de viraje, y que los individuos participantes de nuestro estudio se hacen eco del discurso hegemónico que sostiene la despolitización y apatía de los ' 90 , sesgando las luchas que atravesaron el campo educativo y de los derechos humanos ${ }^{13}$ (Kriger, 2016) así como los activismos territoriales que en los años posteriores marcaron las modalidades de actuación (Bonvillani, Palermo, Vázquez \& Vommaro, 2010).

En las narrativas abordadas, la escuela aparece como una institución democratizadora que promueve el despertar político, donde los jóvenes y las jóvenes no son meramente alumnos y alumnas, sino protagonistas. Se hace notable que cuentan con el reconocimiento adulto, y que, a la vez, lo desafían, extendiendo sus demandas a la toma de decisiones en la escuela y en las políticas públicas.

Respecto de "La noche de los lápices", existe consenso en su reconocimiento dentro de la experiencia escolar como vivencia propiamente estudiantil. Sin embargo, al introducir en el relato la dimensión política aparecen diferencias que vinculamos con la distinción entre "memoria literal" y "memoria

13 Nos referimos especialmente a la defensa de la educación pública, libre y gratuita por parte de docentes y estudiantes, y a la vasta lucha en el campo de los derechos humanos. ejemplar" (Todorov, 2000, p. 11): mientras una propondría "recordar" la historia y reivindicar a los jóvenes secuestradas por la dictadura, la otra buscaría articular lo ocurrido con el presente -desapariciones y violencia policial en democracia- en clave política.

Acerca del "voto joven", encontramos que estos militantes lo valoran positivamente y remarcan que la reactivación política de los jóvenes y su preeminencia en la vida política del país, es previa a la sanción de la Ley, buscando capitalizar la nueva medida a favor del compromiso político de su generación. En pos de ello, proponen modificaciones legales y programáticas en la escuela: habilitar el ingreso de partidos, adaptar las currículas, limitar la intervención adulta, etc.

Nuestro hallazgo más relevante radica en que los jóvenes y las jóvenes se presentan como agentes políticos que se configuran precisamente en el encuentro entre su autocalificación, por prácticas propias -desde abajo- y el reconocimiento adulto -desde arriba-. Imbuidos en esta doble lógica, ubican la escuela como escenario central para el despliegue de iniciativas y de encuentro con la política. Desde allí se proponen expandirlas, en forma de propuestas y/o reclamos, al Estado y a la sociedad.

Como hemos planteado, la subjetivación política es un proceso dinámico, imposible de anclar a una situación específica, que se presenta como horizonte de participación y ciudadanía: si bien todos son sujetos sociales, no todos logran constituirse en sujetos políticos activos. Ahora bien: desde la perspectiva de la sociología de la individuación, que se centra en el proceso de "fabricación de los individuos" (Martuccelli, 2007, p. 21), la noción de prueba es entendida como un reto que articula dimensiones estructurales y subjetivas, a las que todos los individuos deben enfrentarse, bien sea que las superen con éxito o no. ¿Sería posible, entonces, suponer que los jóvenes militantes están afrontando la cuestión de la participación política y su propia formación como sujetos políticos, como si se tratara de una renovada dimensión -en tiempos de reencuentro de pedagogía y política (Kriger, 2010)- de lo que Martuccelli denomina "prueba 
escolar"? Es decir: ¿podríamos pensar la iniciación política en este contexto y para esta población, como un desafío particular inherente al paso por la escuela, que lleva a las personas militantes a ubicarse en una posición ejemplar de responsabilidad frente a sus compañeros y compañeras?

Si así fuera, estos jóvenes estarían viviendo la sub-prueba escolar como reto individual, buscando "superarla", pero esto implicaría, a la vez, una construcción colectiva donde sea dable participar e incluir a sus pares, como en una suerte de desafío generacional. Desde esta hipótesis conjetural, creemos que los militantes que participaron de nuestro estudio se apropian de ciertos rasgos del discurso que -desde arribalos consagra y los vincula a la participación, y echan mano a sus propias tradiciones de lucha y a sus prácticas actuales para ponerse al hombro -desde abajo- la tarea de hacerse sujetos políticos. Sin embargo, ellos no se presentan como unos pocos elegidos para la práctica política, sino que, al identificar la escuela como ámbito para su despliegue, interpelan a toda la juventud, a la que consideran enfrentada al mismo desafío, integrando en este movimiento lo individual y lo colectivo.

\section{Lista de referencias}

Aguiló, V. \& Wahren, J. (2014). Los bachilleratos populares de Argentina como "campos de experimentación social". Argumentos, 27 (74), pp. 97-114.

Araujo, K. \& Martuccelli, D. (2010). La individuación y el trabajo de los individuos. Educaçao e Pesquisa, 36, pp. 77-91.

Arfuch, L. (2002). El espacio biográfico: dilemas de la subjetividad contemporánea. Buenos Aires: Fondo de Cultura Económica.

Berger, P. \& Luckmann, T. (1989 [1968]). La Construcción Social de la Realidad. Buenos Aires: Amorrortu.

Bonvillani, A. (2012). Hacia la construcción de la categoría 'subjetividad política': una posible caja de herramientas y algunas líneas de significación emergentes. En C. Piedrahíta-Echandía, A. Díaz-Gómez \& P. Vommaro (comps.) Subjetividades

Rev.latinoam.cienc.soc.niñez juv 15 (2): 1085-1096, 2017 http://revistalatinoamericanaumanizales.cinde.org.co DOI:10.11600/1692715x.1521920122016 políticas: desafios y debates latinoamericanos. Bogotá, D. C.: Clacso. Bonvillani, A.; Palermo, A.; Vázquez, M. \& Vommaro, P. (2008). Aproximaciones a los estudios acerca de juventud $\mathrm{y}$ prácticas políticas en la Argentina (19682008). Revista Argentina de Sociología, 6 (11), pp. 44-73.

Bonvillani, A.; Palermo, A.; Vázquez, M. \& Vommaro, P. (2010). Del Cordobazo al kirchnerismo. Una lectura crítica acerca de los periodos, temáticas y perspectivas de los estudios sobre juventudes y participación política en Argentina. En S. V. Alvarado \& P. Vommaro (2010). Jóvenes, cultura y política en América Latina: algunos trayectos de sus relaciones, experiencias $y$ lectura (1960-2000). Buenos Aires: Clacso.

Denzin, N. (1989). Interpretive biography. Newbury Park: Sage Publications.

Dubet, F. \& Martuccelli, D. (1998). En la escuela. Sociología de la experiencia escolar. Buenos Aires: Losada.

Dukuen, J. \& Kriger, M. (2016). Solidaridad, esquemas morales y disposiciones políticas en jóvenes de clases altas: hallazgos de una investigación en una escuela del conurbano bonaerense (2014-2015). Córdoba: Nueva Época.

Giarracca, N. (ed.) (2001). La protesta social en la Argentina: transformaciones económicas y crisis social en el interior del país. Buenos Aires: Alianza.

https://www.academia.edu/22351281/ Cambios_en_la_transmisi\%C3\%B3n_y_

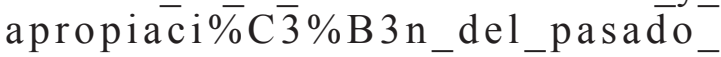
reciente_en_la_escuela._Reflexiones_a partir_de_un_caso_en_la_ciudad_de Buenos_A Aires

Kriger, M. (2010). Jóvenes de escarapelas tomar: escolaridad, enseñanza de la historia y formación política en la Argentina post 2001. La Plata: Edulp.

Kriger, M. (2012). La invención de la juventud, entre la muerte de las naciones y su resurrección. En M. Kriger (comp.) Juventudes en América Latina: abordajes multidisciplinares sobre identidades, culturas y políticas del siglo $\mathrm{XX}$ al siglo 
XXI, (pp. 1-27). Buenos Aires: Caicyt, Conicet.

Kriger, M. (2016). La tercera invención de la juventud. Dinámicas de la politización juvenil en tiempos de la reconstrucción del Estado-Nación (Argentina 2002-2015), Buenos Aires: GEU.

Lefort, C. (1992). El arte de escribir y lo político. Barcelona: Herder.

Lorenz, F. (2006). El pasado reciente en Argentina: las difíciles relaciones entre transmisión, educación y memoria. En M. Carretero, A. Rosa \& F. González (comps.) Enseñanza de la historia y memoria colectiva, (pp. 277-296). Buenos Aires: Paidós.

Manzano, V. (2011). Cultura, política y movimiento estudiantil secundario en la Argentina de la segunda mitad del siglo XX. Propuesta Educativa, 35 (1), pp. 41 52.

Martinic, R. \& Soto, N (2010). La sociología en los tiempos del individuo: entrevista a Danilo Martuccelli. Doble Vínculo, 1 (1), pp. 1-27. Recuperado de:

https://doblevinculo.files.wordpress. com/2011/01/entrevista-a-danilomartuccelli.pdf

Martuccelli, D. (2007). Cambio de rumbo. La sociedad a escala del individuo. Santiago de Chile: LOM.

Martuccelli, D. \& De Singly, F. (2012). Las sociologías del individuo. Santiago de Chile: LOM.

Núñez, P. (2008). La redefinición del vínculo juventud-política en la Argentina: un estudio a partir de las representaciones y prácticas políticas juveniles en la escuela secundaria y media. Manizales: Universidad de Manizales.

Núñez, P. (2012). Comportamientos políticos juveniles desde la transición democrática hasta la 'toma' de escuelas. En M. Kriger (comp.) Juventudes en América Latina: abordajes multidisciplinares sobre identidades, culturas y políticas del siglo $X X$ al siglo XXI. Buenos Aires: CaicytConicet.

Palacios-Mena, N. \& Herrera-González, J. D. (2013). Subjetividad, socialización política y derechos en la escuela. Magis. Revista Internacional de Investigación en Educación, 5 (11), pp. 413-437.

Raggio, S. (2006). En torno a "La noche de los lápices". La batalla por los relatos. Revista Puentes, (18), pp. 32-35.

Romero, L. A. (coord.) (2004). La Argentina en la escuela. La idea de nación en los textos escolares. Buenos Aires: Siglo XXI Editores.

Said, Sh. \& Kriger, M. (2014) Subjetivación política y educación popular: la noción de diálogo en Rancière y Freire como aporte a la reflexión teórico-metodológica sobre Bachilleratos Populares. Question, 1 (42), pp. 405-420.

Said, Sh. \& Kriger, M. (2016). Educación popular y subjetivación política. Aportes de las sociologías del individuo para el estudio de experiencias de jóvenes en Bachilleratos. Crítica y Emancipación (en prensa).

Svampa, M. (2001). Los que ganaron. La vida en los countries y barrios privados. Buenos Aires: Biblos.

Todorov, T. (2000). Los abusos de la memoria. Buenos Aires: Paidós.

Touraine, A. (1997). ¿Podremos vivir juntos? La discusión pendiente: el destino del hombre en la aldea global. Buenos Aires: Fondo de Cultura Económica.

Vázquez, M. (2013). En torno a la construcción de la juventud como causa pública durante el kirchnerismo: principios de adhesión, participación y reconocimiento. Revista Argentina de Estudios de Juventud, (7), pp. $1-25$.

Vázquez, M. (2015). Juventudes, políticas públicas y participación. Un estudio de las producciones socioestatales de juventud en la Argentina reciente. Buenos Aires: GEU.

Vommaro, G.; Morresi, S. \& Bellotti, A. (2015). Mundo Pro: anatomía de un partido fabricado para ganar. Buenos Aires: Planeta.

Vommaro, P. (2015). Juventudes y políticas en la Argentina y en América Latina. Buenos Aires: GEU. 